\title{
Relative contribution of electrical stimulation to beef tenderness compared to other production factors
}

\author{
Manuel Juárez, John A. Basarab, Vern S. Baron, Mercedes Valera, Óscar López-Campos, \\ Ivy L. Larsen, and Jennifer L. Aalhus
}

\begin{abstract}
Aging explained $>45 \%$ of the variability in beef tenderness, whereas electrical stimulation explained $>12 \%$. The effect of electrical stimulation was significant for calf-fed steers up to $27 \mathrm{~d}$ of aging. However, this effect did not persist beyond $6 \mathrm{~d}$ of aging for yearling-fed steers. However, electrical stimulation prevents cold toughening in lighter, leaner carcasses.
\end{abstract}

Key words: aging, carcass, cold toughening, fat thickness, shear force.

Résumé : Le vieillissement explique $>45 \%$ de la variabilité dans la tendreté du bœuf( $>45 \%)$, tandis que la stimulation électrique explique $>12 \%$. L'effet de la stimulation électrique était significatif chez les jeunes bovins jusqu'à 27 jours de vieillissement. Par contre, l'effet ne persistait pas au-delà de 6 jours de vieillissement dans le groupe de bovins d'un an. La stimulation électrique prévient le durcissement à froid dans les carcasses plus légères et moins grasses.

Mots-clés : vieillissement, carcasse, durcissement à froid, épaisseur de gras, forces de cisaillement.

\section{Introduction}

Electrical stimulation is a well-known technology currently used in Canada, which has been reported to reduce tenderness variation in beef cattle (Savell et al. 1978). The benefits of electrical stimulation on meat tenderness can be explained by several mechanisms, including prevention of cold toughening by faster postmortem $\mathrm{pH}$ drop, calpain-induced proteolysis, and physical muscle damage (Dransfield 1992; Huff-Lonergan et al. 1995; Koohmaraie 1996; Simmons et al. 2008).

The beef industry has become concerned regarding the efficacy of electrical stimulation in improving tenderness as beef carcass weight and fatness increase (López-Campos et al. 2012). As carcass weight and fat thickness depend on numerous production factors, such as genotype, production system (age and diet), or growth promotants, all these factors may show interactive effects with the use of electrical stimulation in beef carcasses. In addition, previous results (Juárez et al. 2012) have demonstrated that aging time has the largest impact on beef tenderness when compared with other pre- and postmortem factors, such as breed, production system, growth promotants, or carcass suspension.

Consequently, the objective of this study was to determine both the efficacy and the relative contribution of electrical stimulation on beef tenderness compared to other production and processing factors, as well as their potential interactions.

\section{Materials and Methods}

All dietary treatments and experimental procedures were approved by the Lacombe Research Centre Animal Care Committee (Lacombe, AB, Canada), according to the guidelines from the Canadian Council on Animal Care (CCAC 2009). The management of the animals has been previously described in detail by Juárez

Received 25 February 2015. Accepted 11 December 2015.

M. Juárez, V.S. Baron, Ó. López-Campos, I.L. Larsen, and J.L. Aalhus. Agriculture and Agri-Food Canada, Lacombe Research Centre, Lacombe, AB T4L 1W1, Canada.

J.A. Basarab. Alberta Agriculture and Rural Development, Lacombe Research Centre, Lacombe, AB T4L 1W1, Canada.

M. Valera. Departamento de Ciencias Agroforestales, Universidad de Sevilla, 41013 Seville, Spain.

Corresponding author: Manuel Juárez (email: Manuel.Juarez@agr.gc.ca).

(C) Her Majesty the Queen in right of Canada 2016. This work is licensed under a Creative Commons Attribution 4.0 International License (CC BY 4.0), which permits unrestricted use, distribution, and reproduction in any medium, provided the original author(s) and source are credited.

A correction was made to the e-First version of this paper on 20 May 2016 prior to the final issue publication. The current online and print versions are identical and both contain the correction. 
Table 1. Full model adjustment $\left(R^{2}\right)$ and relative contribution (\% within model) of individual factors to the final variation in beef (longissimus muscle) tenderness traits.

\begin{tabular}{lccc}
\hline & Shear force & Initial tenderness & Overall tenderness \\
\hline $\mathbf{R}^{\mathbf{2}}$ & 0.72 & 0.65 & 0.68 \\
\hline Breed-cross (Bc) & 3.52 & 3.38 & 5.85 \\
Sire & 8.63 & 8.45 & 8.90 \\
Production system (Ps) & 5.21 & 4.58 & 3.18 \\
Implant (Imp) & 1.92 & 8.12 & 6.12 \\
$\beta$-Agonist ( $\beta$ ag) & 0.29 & 0.79 & 0.00 \\
Electrical stimulation (Es) & 13.2 & 12.2 & 14.0 \\
Aging (Age) & 50.0 & 47.0 & 45.1 \\
Bc $\times$ Imp & 3.12 & 2.21 & 5.33 \\
Ps $\times$ Es & 5.34 & 3.23 & 4.80 \\
\hline
\end{tabular}

Note: Only interactions explaining $>5 \%$ for any trait are reported.

et al. (2012). Briefly, 112 steers (4 breed-crosses: $>75 \%$ Continental, 50-75\% Continental, 50-75\% British, $>75 \%$ British) were arranged in a $2 \times 2 \times 2$ factorial experimental design including production system (12-13 mo, grain finished calf-fed vs. 18-20 mo, grain finished yearling-fed), implant (not implanted vs. implanted with $200 \mathrm{mg}$ progesterone and $20 \mathrm{mg}$ estradiol benzoate at weaning followed by $120 \mathrm{mg}$ of trenbolone acetate and $24 \mathrm{mg}$ estradiol after every 80-90 d interval until slaughter), and $\beta$-adrenergic agonist (no ractopamine vs. $200 \mathrm{mg}$ ractopamine head ${ }^{-1} \mathrm{~d}^{-1}$ for $28 \mathrm{~d}$ before slaughter). Steers were slaughtered at the AAFC Lacombe Research Centre federally inspected research abattoir following commercial practices when animals reached a constant back fat thickness of 8-9 $\mathrm{mm}$ determined by ultrasound. After slaughter, hot carcass weight was measured and high voltage stimulation was applied to the right side of the carcass after splitting ( 40 min postmortem) via a manual probe inserted into the ligamentum nuchae, using a Koch-Britton Stimulator (Koch-Britton, Kansas City, MO; 470 V, $60 \mathrm{~Hz}$, 1.5 A for $1 \mathrm{~min}$ ). Temperature loggers (Mark III, MC4000, Sumaq Wholesalers, Toronto, ON) were used to track temperature decline at the center of the longissimus muscle in both sides of the carcass, and $\mathrm{pH}$ was measured at $45 \mathrm{~min}$ and at $24 \mathrm{~h}$ postslaughter (at the 6th/7th thoracic) using a Fisher Scientific Accumet 1002 pH/temperature meter equipped with an Orion Ingold electrode (Ingold Messtechnik AG, Udorf, Switzerland), as reported by Tullio et al. (2014). The carcasses were chilled at $2{ }^{\circ} \mathrm{C}$ overnight for $24 \mathrm{~h}$. At $24 \mathrm{~h}$ after slaughter, the longissimus muscles from both carcass sides were removed. Controlling for location effects, longissimus muscles were fabricated into steaks in order to analyze instrumental and sensory tenderness at 2, 6, 13, 21, and $27 \mathrm{~d}$ after slaughter. Samples were also used to evaluate sarcomere length and collagen content using methodologies described by Juárez et al. (2012). Briefly, steaks were grilled (Garland Grill ED30B, Condon Barr Food Equipment Ltd., Edmonton, $A B$ ) to an internal temperature of $71^{\circ} \mathrm{C}$. For shear force evaluation, steaks were transferred to a $1^{\circ} \mathrm{C}$ cooler for $24 \mathrm{~h}$, and then six cores, $1.9 \mathrm{~cm}$ in diameter and parallel to the fiber grain, were analyzed using a TA-XT Plus Texture Analyzer equipped with a WarnerBratzler shear head at a crosshead speed of $20 \mathrm{~cm} \mathrm{~min}^{-1}$ (Texture Technologies Corp., Hamilton, MA). To measure sarcomere length, $2 \mathrm{~g}$ of muscle freed of fat and connective tissues were removed, scissor-minced, and mixed in $20 \mathrm{~mL}$ of a $0.02 \mathrm{M}$ EGTA/0.25 M sucrose solution and homogenized for $10 \mathrm{~s}$ at $6000 \mathrm{rev} \mathrm{min}^{-1}$. One drop of each sample was placed on a slide with a cover slip for observation with an Axioscope (Zeiss, Germany). Three sarcomere lengths were measured per image. Soluble and insoluble collagen contents were quantified by determination of the hydroxyproline content. The factor 7.52 was used to convert the hydroxyproline content to the soluble collagen content and the factor 7.25 was used to convert to insoluble collagen content. For sensory evaluation, attribute ratings from trained panelists (eight members) were electronically collected with Compusense 5, release 4.6 computer software (Compusense Inc., Guelph, ON) using an 8-point descriptive scale for initial and overall tenderness $(1=$ extremely tough; $8=$ extremely tender).

Statistical analyses were developed using the MIXED model Covtest procedure of SAS (SAS, 2003), including the individual ante- and postmortem factors and their interactions. The degree of fatness, nested within treatments, was used as a covariate. The adjusted multiple $R^{2}$ was calculated, as described by Juárez et al. (2012). Individual factors were then removed from the model, and the decrease in the $R^{2}$ value was used to calculate the relative contribution of a given factor on the variability observed for each measured trait. Main effects and interactions that explained $>5 \%$ of the variability for any of the variables were included in the tables. Least-squares means were generated for the over time interaction between the production system and electrical stimulation $(P<0.05)$, and a PDIFF test was used for means separation.

\section{Results and Discussion}

The variability explained by the model (Table 1) for instrumental tenderness $\left(R^{2}=0.72\right)$, as well as for 
Fig. 1. Shear force value in function of production system, electrical stimulation and ageing time.

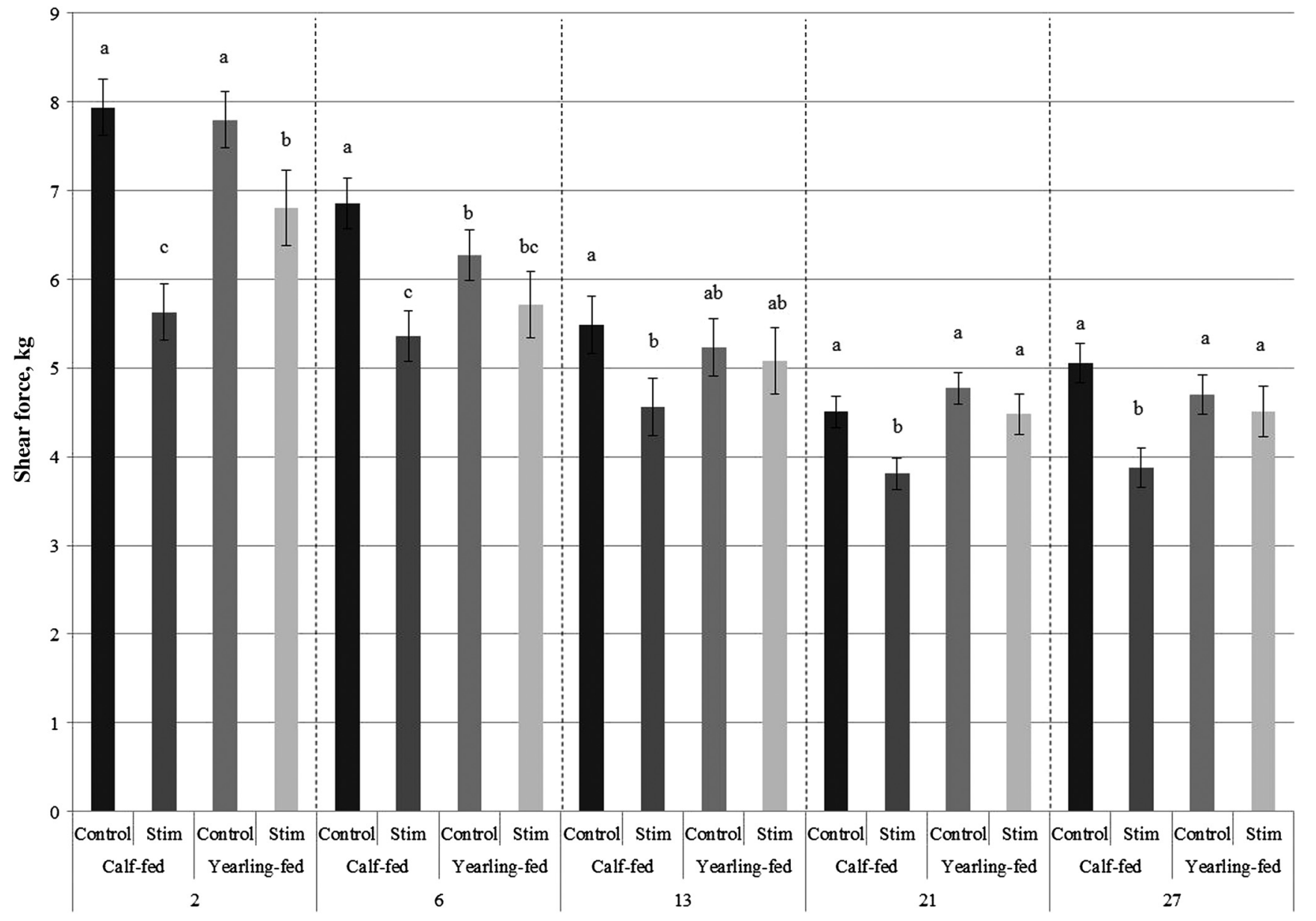

both sensory initial $\left(R^{2}=0.65\right)$ and overall tenderness $\left(R^{2}=0.68\right)$, was mainly due to the postmortem aging process (50.0, 47.0, and 45.1\%, respectively). Electrical stimulation was the second most influential factor, explaining $>12 \%$ of the variability for all three instrumental and sensory tenderness traits. The interaction between the production system (calf-fed vs. yearling-fed) and electrical stimulation also explained $\sim 5 \%$ of the variability in shear force and overall tenderness. The production system and its interaction with electrical stimulation were responsible for 5.2 and $5.3 \%$ of the variability in shear force, respectively. Another important factor was sire (nested within breed-cross), explaining $>8 \%$ of the variability in these traits. The effect of the implant strategy was higher in sensory traits (8.1 and 6.1\% for initial and overall tenderness, respectively) than in shear force $(1.9 \%)$. The effect of $\beta$-adrenergic agonist was minimal $(<1 \%)$ for all three variables. In a previous study by Juárez et al. (2012), using the same experimental design but with carcass suspension as the early postmortem intervention, similar results were reported for shear force values and sarcomere length. Regarding sensory traits, the effect of aging was lower and the effect of the suspension treatment and its interaction with aging was higher than observed when electrical stimulation was used. Aging, suspension, and their interaction together explained $>65 \%$ of the variability in instrumental and sensory tenderness. In the case of altered suspension, rigor sarcomere shortening decreased due to aitch bone suspension, increasing tenderness and reducing the effect of proteolysis during aging on meat texture (Koohmaraie 1996). In the present study, the interaction between aging and electrical stimulation was significant $(P<0.05)$, but it did not explain $>5 \%$ of the variability of any of the studied traits (data not shown). Furthermore, electrical stimulation had no effect $(P>0.05)$ on sarcomere length and percentage of soluble collagen (average: 1.82 \pm $0.03 \mu \mathrm{m}$ and $6.72 \pm 0.42 \%$, respectively, data not shown).

Electrical stimulation prevents cold toughening after slaughter by accelerating the $\mathrm{pH}$ fall $(24 \mathrm{~h} \mathrm{pH}=5.56$ vs. 5.67 for stimulated and control carcass sides, respectively, $P<0.001)$ and, consequently, reduces the need for an extended aging process to resolve the rigor contraction (Simmons et al. 2008). Calpain-induced proteolysis and physical muscle damage have also been suggested as part of the mechanism involved with the lower shear force values observed in meat from electrically stimulated beef (Dransfield 1992; Huff-Lonergan et al. 1995; Koohmaraie 
1996). Similar to altered carcass suspension (Juárez et al. 2012), further proteolysis during aging decreased differences over time ( shear force $=4.06 \mathrm{vs}$. $4.96 \mathrm{~kg}$ for electrical stimulation and control, respectively). Figure 1 shows the interaction between the production system and electrical stimulation $(P=0.012)$ at different aging times $(2,6,13,21$, and $27 \mathrm{~d}$ of aging). Electrical stimulation resulted in lower $(P<0.05)$ shear force in beef from calf- and yearling-fed production systems after $2 \mathrm{~d}$ of aging with a greater effect on meat from calf-fed steers. Six days after slaughter, the differences in shear force between meat from control and electrically stimulated carcasses had disappeared for the yearling-fed production system $(P>0.05)$. However, the effect of electrical stimulation on calf-fed carcasses was significant $(P<$ 0.05) up to 27 d postmortem. Similar effects were observed on initial and overall tenderness (data not shown). Carcass weight and composition are both important factors determining the chilling rate (average calf-fed production system carcass weight $=250 \mathrm{~kg}$; grade fat $=11.4 \mathrm{~mm}$; average yearling-fed animals carcass weight $=326 \mathrm{~kg}$; grade fat $=13.3 \mathrm{~mm}$ ). Cold toughening occurs when meat temperature falls below $8-10{ }^{\circ} \mathrm{C}$ while the $\mathrm{pH}$ is above 6 and is more common in carcasses with thin fat covering (Dikeman and Devine, 2014). Heavier and fatter carcasses decrease the chilling rate because of greater amount of insulation or because of an increase in total mass (Savell et al. 2005). Indeed, in the present study, longissimus muscle temperatures at $10 \mathrm{~h}$ postmortem averaged 8.9 and $9.8^{\circ} \mathrm{C}$ in calf-fed and yearling-fed carcasses, respectively.

Thus, leaner/lighter carcasses undergoing rigorous chilling would show greater benefit from electrical stimulation (Savell et al. 1978). Electrical stimulation was developed in the 1970s and 1980s, when $350 \mathrm{~kg}$ carcasses were considered heavy carcasses. However, carcass weights have continued to increase since that time; in Canada, typical carcass weights for steer carcasses increased from $\sim 260 \mathrm{~kg}$ in 1970 to $390 \mathrm{~kg}$ in 2011 (Romahn 2012). In addition, beef carcasses in Canada have shown an increase in fatness during the last 10 years (Aalhus et al. 2014). Under the same chilling conditions, these changes in carcass weight and fatness may lead to reduced cold toughening, limiting the overall effect of electrical stimulation on the final tenderness of beef.

Based on results from the present study and previous literature, electrical stimulation can reduce the variability in beef tenderness in light carcasses by preventing cold toughening. Its efficacy using electrical conditions similar to the present study may be limited in heavy carcasses. As beef carcasses in Canada are getting heavier and fatter, the impact of industry electrical stimulation conditions on Canadian beef tenderness should be re-evaluated. Further research should focus on potential changes in the parameters used to electrically stimulate carcasses to increase the efficacy through alternative mechanisms (for example, physical damage to the connective tissue) and to recommend practical thresholds for carcass weight and fatness at which electrical stimulation loses efficacy.

\section{Acknowledgements}

Financial support was received from the Alberta Livestock and Meat Agency Ltd., Alberta Agriculture and Rural Development (ARD), Agriculture and Agri-Food Canada (AAFC) Matching Initiatives Program, Alberta Environment and Elanco Animal Health. The authors gratefully acknowledge the in-kind contribution in animals, facilities, and people received from AAFC Lacombe.

\section{References}

Aalhus, J.L., López-Campos, O., Prieto, N., Rodas-Gonzalez, A., Dugan, M.E.R., Uttaro, B., and Juárez, M. 2014. Review Canadian Beef Grading-Opportunities to identify carcass and meat quality traits valued by consumers. Can. J. Anim. Sci. 94(4): 545-556. doi:10.4141/cjas-2014-038.

Canadian Council on Animal Care. 2009. CCAC guidelines on: the care and use of farm animals in research, teaching and testing. Canadian Council on Animal Care, Ottawa, ON, Canada.

Dikeman, M., and Devine, C.E. 2014. Optimization of Sensory and Meat Quality. In C.E. Devine, and M. Dikeman, eds. Encyclopedia of Meat Sciences. 2nd ed., Elsevier Academic Press, Oxford, UK.

Dransfield, E. 1992. Modelling post-mortem tenderization - III: Role of calpain I in conditioning. Meat Sci. 31(1): 85-94. doi: 10.1016/0309-1740(92)90074-E. PMID:22059512.

Huff-Lonergan, E., Parrish, F.C., Jr., and Robson, R.M. 1995. Effects of postmortem aging time, animal age, and sex on degradation of titin and nebulin in bovine longissimus muscle. J. Anim. Sci. 73(4): 1064-1073. PMID:7628949.

Juárez, M., Basarab, J.A., Baron, V.S., Valera, M., Larsen, I.L., and Aalhus, J.L. 2012. Quantifying the relative contribution of ante- and post-mortem factors to the variability in beef texture. Animal, 6(11): 1878-1887. doi:10.1017/S1751731112000572. PMID:23031348.

López-Campos, Ó., Aalhus, J.L., Uttaro, B., Dugan, M.E.R., and Juárez, M. 2012. Ten year trends in the Canadian Beef Quality and Lean Meat Yield Grades. Pages 9, 2012 Annual Conference and Technical Symposium Canadian Meat Science Association (CMSA) and Canadian Meat Council (CMC), Québec City, QC, Canada.

Koohmaraie, M. 1996. Biochemical factors regulating the toughening and tenderization processes of meat. Meat Sci. 43(Suppl. 1): S193-S201. doi:10.1016/0309-1740(96)00065-4. PMID:22060651.

Romahn, J. 2012. Beef carcass weights reaching limit. Agri 007. [Online] Available: http://agri007.blogspot.ca/2012/07/ beef-carcass-weights-reaching-limit.html [accessed March 2015].

SAS. 2003. SAS ${ }^{\circledR}$ user's guide: Statistics. SAS for Windows, version 9.1. SAS Institute, Inc., Cary, NC, USA.

Savell, J.W., Mueller, S.L., and Baird, B.E. 2005. The chilling of carcasses. Meat Sci. 70: 449-459. doi:10.1016/j.meatsci.2004.06.027.

Savell, J.W., Smith, G.C., and Carpenter, Z.L. 1978. Beef quality and palatability as affected by electrical stimulation and cooler aging. J. Food Sci. 43(6): 1666-1668. doi:10.1111/jfds.1978.43. issue-6.

Simmons, N.J., Daly, C.C., Cummings, T.L., Morgan, S.K., Johnson, N.V., and Lombard, A. 2008. Reassessing the principles of electrical stimulation. Meat Sci. 80(1): 110-122. doi: 10.1016/j.meatsci.2008.05.006. PMID:22063176.

Tullio, R., Juárez, M., Larsen, I.L., Basarab, J., and Aalhus, J.L. 2014. Influence of some meat quality parameters on beef tenderness. Can. J. Anim. Sci. 94(3): 455-458. doi:10.4141/ cjas2013-157. 